\title{
Glycyrrhizic acid improved lipoprotein lipase expression, insulin sensitivity, serum lipid and lipid deposition in high-fat diet-induced obese rats
}

\author{
Chia Hui Apphia Eu', Wai Yen Alfred Lim', So Ha Ton ${ }^{1 *}$, Khalid bin Abdul Kadir²
}

\begin{abstract}
Background: The metabolic syndrome, known also as the insulin resistance syndrome, refers to the clustering of several risk factors for atherosclerotic cardiovascular disease. Dyslipidaemia is a hallmark of the syndrome and is associated with a whole body reduction in the activity of lipoprotein lipase ( $L P L)$, an enzyme under the regulation of the class of nuclear receptors known as peroxisome proliferator-activated receptor (PPAR). Glycyrrhizic acid (GA), a triterpenoid saponin, is the primary bioactive constituent of the roots of the shrub Glycyrrhiza glabra. Studies have indicated that triterpenoids could act as PPAR agonists and GA is therefore postulated to restore LPL expression in the insulin resistant state.

Results: Oral administration of $100 \mathrm{mg} / \mathrm{kg}$ of GA to high-fat diet-induced obese rats for 28 days led to significant reduction in blood glucose concentration and improvement in insulin sensitivity as indicated by the homeostasis model assessment of insulin resistance (HOMA-IR) $(p<0.05)$. LPL expression was up-regulated in the kidney, heart, quadriceps femoris, abdominal muscle and the visceral and subcutaneous adipose tissues but down-regulated in the liver - a condition in reverse to that seen in high-fat diet-induced obese rats without GA. With regard to lipid metabolism, GA administration led to significant hypotriglyceridemic and HDL-raising effects $(p<0.05)$, with a consistent reduction in serum free fatty acid, total cholesterol and LDL cholesterol and significant decrease in tissue lipid deposition across all studied tissue $(p<0.01)$.

Conclusion: In conclusion, GA may be a potential compound in improving dyslipidaemia by selectively inducing LPL expression in non-hepatic tissues. Such up-regulation was accompanied by a GA-mediated improvement in insulin sensitivity, which may be associated with a decrease in tissue lipid deposition. The HDL-raising effect of GA suggests the antiatherosclerotic properties of GA.
\end{abstract}

\section{Background}

The metabolic syndrome (MetS), known also as the insulin resistance syndrome and syndrome $\mathrm{X}$, refers to the clustering of several risk factors for atherosclerotic cardiovascular disease. Insulin resistance (IR) is recognized as the potential underlying etiology of the various metabolic abnormalities that comprises the syndrome, of which includes abdominal obesity, glucose intolerance, atherogenic dyslipidaemia and hypertension. Individuals with the syndrome are at a 2 - and 5-fold

\footnotetext{
* Correspondence: ton.so.ha@sci.monash.edu.my

'School of Science, Monash University Sunway Campus, Jalan Lagoon

Selatan, Bandar Sunway 46150, Selangor Darul Ehsan, Malaysia

Full list of author information is available at the end of the article
}

increased risk for the development of cardiovascular diseases and diabetes mellitus respectively [1-3].

Various studies have shown that with the development of IR, the production and activity of the enzyme lipoprotein lipase (LPL) is reduced [4,5]. LPL acts to hydrolyze the core triacylglycerol (TAG) of circulating TAG-rich lipoproteins to regulate the entry of fatty acids into the underlying tissues $[5,6]$. Reduced LPL activity has been shown to lead to an inhibition in the lipolytic rate of the chylomicrons and the very-low-density lipoproteins (VLDL), triggering the development of hypertriglyceridaemia and the subsequent dyslipidaemia seen in the MetS $[7,8]$.

Stimulation of LPL activity by either the use of transgenic overexpression or the administration of LPL- 
raising drugs has been shown to ameliorate the observed dyslipidaemia. Systemic overexpression of the human LPL transgene in Watanabe heritable hyperlipidemic (WHHL) rabbits which mimic the features of MetS in humans, for example, led to a significant decrease in plasma TAG levels and corrected the hypercholesterolemia in these animal models [9]. In addition, targeted over-expression of LPL in skeletal muscle of transgenic mice lowered both plasma TAG and FFA levels even upon high-fat feeding [10].

Currently available classes of LPL-raising drugs include the fibrates, thiazolidinediones (TZDs) and the NO-1886 (ibrolipim). Both the fibrates and TZD are peroxisome proliferator-activated receptor (PPAR) agonists that act on the isoforms PPAR- $\alpha$ [7] and PPAR- $\gamma$ [11] respectively to induce an increase in LPL activity. These PPAR nuclear receptors then bind to the peroxisome proliferator response element (PPRE) present in the promoter region of the LPL gene [12]. Despite the effectiveness of fibrates however, patients on long-term fibrate therapy suffer from an increased incidence of cholesterol gallstone [13]. The TZDs on the other hand is associated with fluid retention and plasma volume expansion which lead to peripheral edema. This increases the incidence of heart failure in some patients, with a frequency of 2.5 times greater in patients on combination therapy with insulin [14]. Lastly, NO-1886 has been reported to inhibit basal and adrenocorticotrophic hormone (ACTH)-induced release of steroid hormones in rat, dog, monkey and human adrenocortical cells, resulting in hypertrophy of the adrenals [15]. With such drawbacks, the development of an alternative LPL-promoting agent is therefore needed.

Glycyrrhizic acid (GA), a triterpenoid saponin, is the primary bioactive constituent of the roots of the shrub Glycyrrhiza glabra. Interest in GA arose following discoveries that excess tissue glucocorticoid action, amplified by the enzyme $11 \beta$-hydroxysteroid dehydrogenase type 1 (11 $\beta$-HSD1), could promote the symptoms of the MetS. GA and its active metabolite glycyrrhetic acid act as potent inhibitors of $11 \beta$-HSD1 [16]. More importantly however, is that triterpenoids had been discovered to act as PPAR agonists $[17,18]$ and this may suggest that GA could also potentially act to activate the PPAR class of nuclear receptors and may therefore be proposed to be a candidate for raising LPL. In this study, the expression of LPL, insulin sensitivity and lipid parameters are compared between high-fat diet-induced obese rats treated and non-treated with GA.

\section{Results}

\section{GA treatment restored LPL expression in obese-induced} rats

In comparing between rats on normal diet (group A) and rats on high-fat diet (group B), LPL expression was downregulated in all tissues in the latter except the liver (Figure 1). The heart showed the highest decrease with a fold difference of $-4.184 \pm 0.25$, followed by the abdominal muscle (AM) $(-4.059 \pm 0.31)$, kidney $(-2.483 \pm 0.32$ fold), subcutaneous adipose tissue (SAT) $(-2.924 \pm 0.39$ fold), quadriceps femoris (QF) $(-1.970 \pm$ $0.65)$ and visceral adipose tissue (VAT) $(-1.361 \pm 0.76)$. No significant differences were seen in any of the tissues when comparing the two groups ( $p>0.05)$. In the liver, LPL was up-regulated by $1.539 \pm 1.10$ fold $(\mathrm{p}>0.05)$. When comparing rats from group $B$ with group $C$ (rats on high-fat diet and given $100 \mathrm{mg} / \mathrm{kg}$ of GA), the reverse was observed where LPL expression was upregulated in all tissues in the latter group (Figure 2) except the liver. The highest up-regulation was observed in the QF (fold difference $=2.786 \pm 2.22$ ) followed by the AM $(2.715 \pm 2.65)$, heart $(2.076 \pm 1.78)$, SAT $(1.935 \pm 1.89)$, kidney $(1.486 \pm 1.38)$ and VAT $(1.058 \pm$ $0.35)$. These increases were not significant $(\mathrm{p}>0.05)$. LPL expression in the liver was down-regulated by a fold of $-1.443 \pm 0.71$ and this was not significant $(p>0.05)$.

\section{GA treatment improved insulin sensitivity in obese- induced rats}

Mean blood glucose concentrations of rats from groups $\mathrm{A}, \mathrm{B}$ and $\mathrm{C}$ were $5.63 \pm 0.92 \mathrm{mmol} / \mathrm{L}, 7.60 \pm 1.35$ $\mathrm{mmol} / \mathrm{L}$ and $4.57 \pm 0.30 \mathrm{mmol} / \mathrm{L}$ respectively (Figure 3 ). Rats from group $C$ presented a significant decrease compared to group $B(p<0.05)$ but non-significant decrease compared to group $A(p>0.05)$. Mean serum insulin concentrations of rats from groups $\mathrm{A}, \mathrm{B}$ and $\mathrm{C}$ were

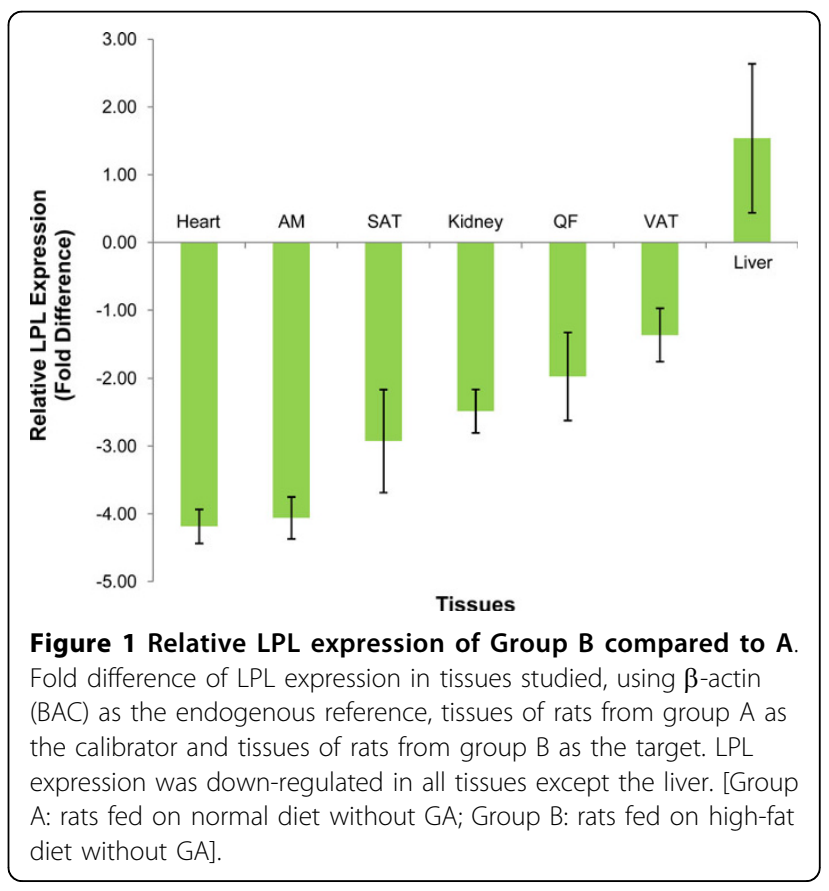




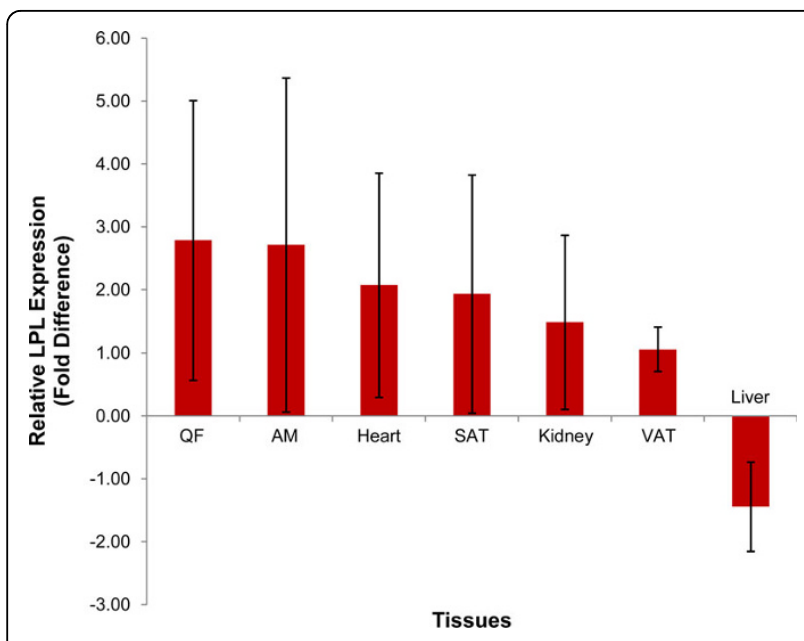

Figure 2 Relative LPL expression of Group C compared to B. Fold difference of $L P L$ expression in tissues studied, using BAC as the endogenous reference, tissues of rats from group $B$ as the calibrator and tissues of rats from group $C$ as the target. LPL expression was up-regulated in all tissues except the liver. [Group B: rats fed on high-fat diet without GA; Group C: rats fed on high-fat diet and given $100 \mathrm{mg} / \mathrm{kg}$ of GA].

$0.37 \pm 0.07 \mathrm{ng} / \mathrm{mL}, 0.73 \pm 0.08 \mathrm{ng} / \mathrm{mL}$ and $0.65 \pm 0.09$ $\mathrm{ng} / \mathrm{mL}$ respectively (Figure 4 ). This represented a significant increase when comparing between group A with groups $B(p<0.05)$ and $C(p<0.05)$. However no significant difference was seen between groups $B$ and $C$ ( $p>0.05$ ). Analysis of the HOMA-IR showed that rats from group $\mathrm{B}(0.23 \pm 0.03)$ had the highest HOMA-IR index compared to groups $\mathrm{A}(0.11 \pm 0.02)$ and $\mathrm{C}(0.12$ \pm 0.02 ) with a significant increase in groups $B$ relative to $A(p<0.01)$ but a non-significant increase in groups

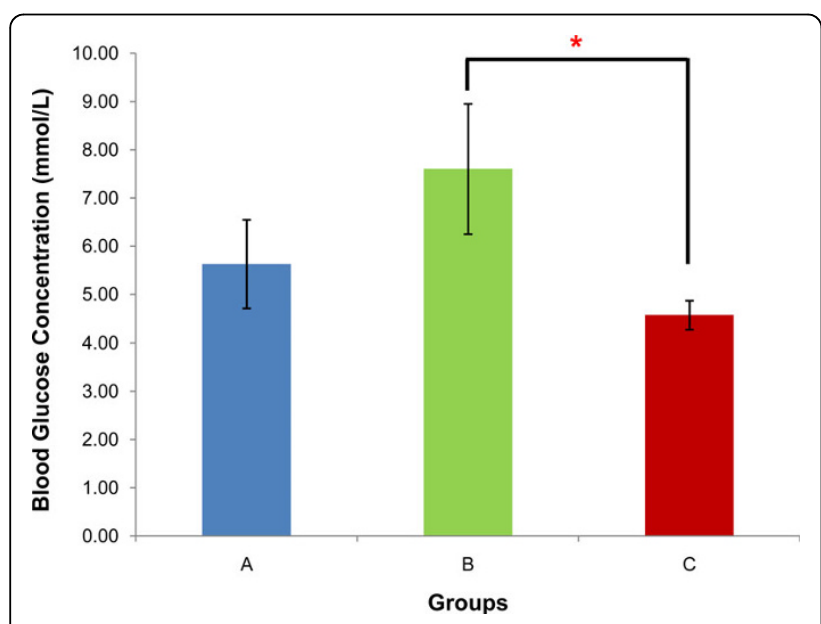

Figure 3 Comparison of blood glucose. Mean concentration of blood glucose $(\mathrm{mmol} / \mathrm{L})$ of rats from groups $A, B$ and $C$. * indicates $p<0.05$ when compared between groups. [Group A: rats fed on normal diet without GA; Group B: rats fed on high-fat diet without GA; Group C: rats fed on high-fat diet and given $100 \mathrm{mg} / \mathrm{kg}$ of GA].

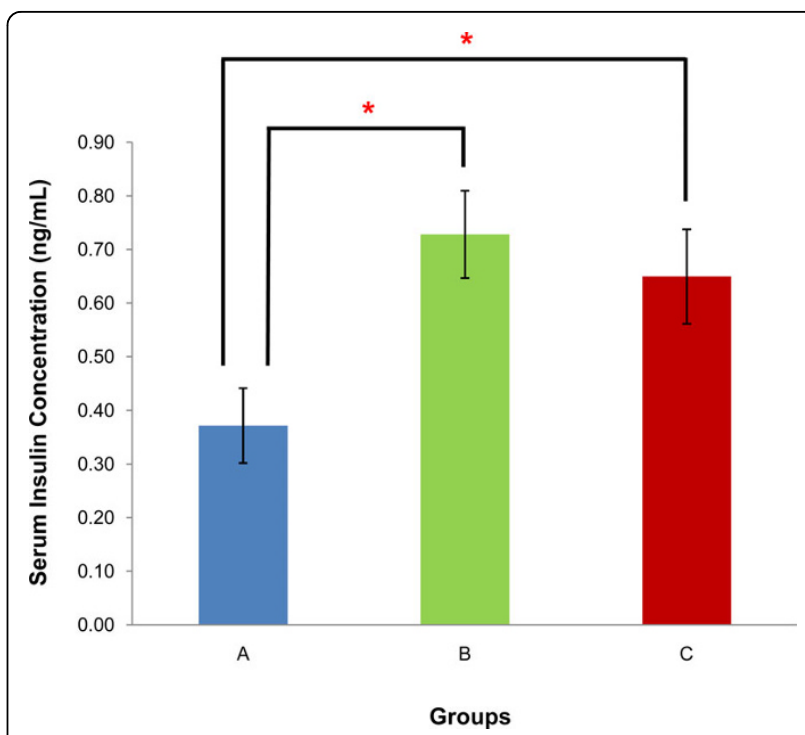

Figure 4 Comparison of serum insulin. Mean concentration of serum insulin $(\mathrm{ng} / \mathrm{mL})$ of rats from groups $A, B$ and $C$. * indicates $p$ $<0.05$ when compared between groups. [Group A: rats fed on normal diet without GA; Group B: rats fed on high-fat diet without GA; Group C: rats fed on high-fat diet and given $100 \mathrm{mg} / \mathrm{kg}$ of GA].

C relative to A ( $p>0.05)$. The HOMA-IR index decrease in group $\mathrm{C}$ was significant compared to group $B(\mathrm{p}<0.05)$ (Figure 5).

\section{GA treatment led to a positive shift in serum lipid in} obese-induced rats

Overall, rats from group $\mathrm{C}$ had improved lipid profile with a $6.80 \%$ decrease in total cholesterol, $22.33 \%$

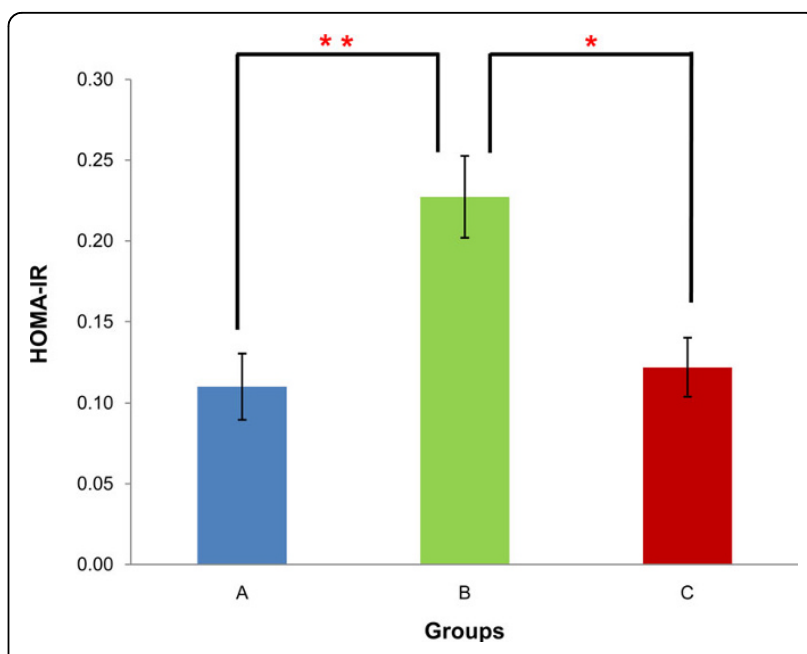

Figure 5 Comparison of HOMA-IR. Mean HOMA-IR of rats from groups $A, B$ and $C$. ** indicates $p<0.01$ and * indicates $p<0.05$ when compared between groups. [Group A: rats fed on normal diet without GA; Group B: rats fed on high-fat diet without GA; Group C: rats fed on high-fat diet and given $100 \mathrm{mg} / \mathrm{kg}$ of GA]. 
decrease in TAG, $13.33 \%$ decrease in LDL, $12.21 \%$ increase in HDL and $7.32 \%$ decrease in serum FFA (Figure 6). Comparison of lipid profiles of rats from groups $\mathrm{A}, \mathrm{B}$ and $\mathrm{C}$ showed that mean total cholesterol was the highest in rats from group $B(2.94 \pm 0.94$ $\mathrm{mmol} / \mathrm{L})$ compared to groups A $(2.60 \pm 0.32 \mathrm{mmol} / \mathrm{L})$ and $\mathrm{C}(2.74 \pm 0.14 \mathrm{mmol} / \mathrm{L})$. No significant difference was observed between all groups. TAG concentrations in groups $\mathrm{A}, \mathrm{B}$ and $\mathrm{C}$ were $0.58 \pm 0.02,1.03 \pm 0.07$ and $0.80 \pm 0.07 \mathrm{mmol} / \mathrm{L}$ respectively. A significant increase (77.59\%) was observed in group B compared to A ( $\mathrm{p}<$ 0.01 ) while a significant decrease $(22.33 \%$ ) was seen in group $\mathrm{C}$ compared to $\mathrm{B}(\mathrm{p}<0.05)$. HDL concentrations in groups $\mathrm{A}, \mathrm{B}$ and $\mathrm{C}$ were $1.86 \pm 0.16,1.72 \pm 0.05$ and $1.93 \pm 0.06 \mathrm{mmol} / \mathrm{L}$ respectively and this represented a significant increase (12.21\%) in group C compared to B $(\mathrm{p}<0.05)$. LDL concentrations showed no significant difference between all three groups which has a level of $0.55 \pm 0.15$ (group A), $0.75 \pm 0.11$ (group B) and $0.65 \pm$ 0.12 (group C) mmol/L respectively. Lastly, FFA levels were $1.05 \pm 0.04,1.23 \pm 0.16$ and $1.14 \pm 0.14 \mathrm{mmol} / \mathrm{L}$ respectively for groups $\mathrm{A}, \mathrm{B}$ and $\mathrm{C}$ with no significant difference between any groups.

\section{GA treatment reduced tissue lipid deposition in obese- induced rats}

Tissue lipid deposition was significantly increased in all tissues of groups B and C compared to A, and was significantly reduced in all tissues of group $C$ compared to $B(p<0.01$ in all cases) (Figure 7 ). Mean lipid deposition in all the five lobes of the liver from groups $\mathrm{A}, \mathrm{B}$ and $\mathrm{C}$ were $8.88 \times 10^{2} \pm 5.45 \mathrm{AU}, 1.46 \times 10^{3} \pm 9.06 \mathrm{AU}$ and $1.07 \times 10^{3} \pm 3.64$ AU respectively. This represented

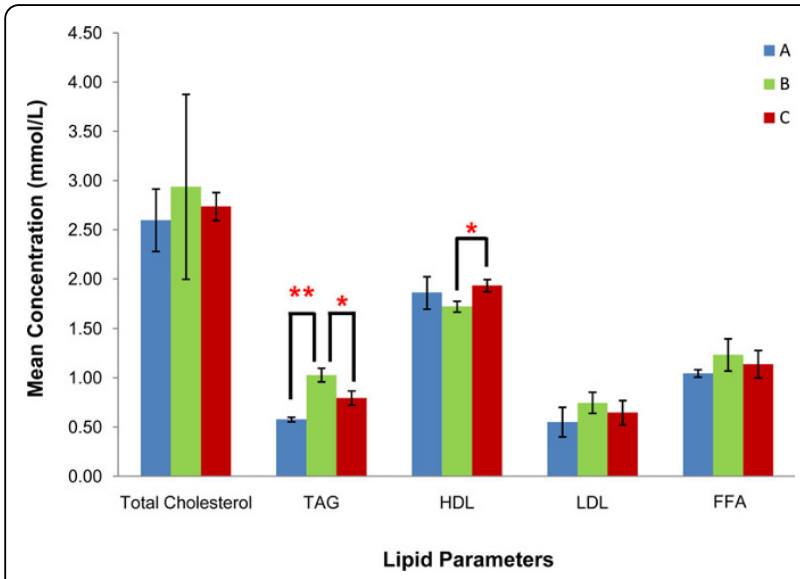

Figure $\mathbf{6}$ Comparison of serum lipid. Mean concentration of total cholesterol, TAG, HDL-cholesterol, LDL-cholesterol and serum FFA in rats from groups $A, B$ and $C$. ${ }^{* *}$ indicates $p<0.01$ and * indicates $p$ $<0.05$ when compared between groups. [Group A: rats fed on normal diet without GA; Group B: rats fed on high-fat diet without GA; Group C: rats fed on high-fat diet and given $100 \mathrm{mg} / \mathrm{kg}$ of GA].

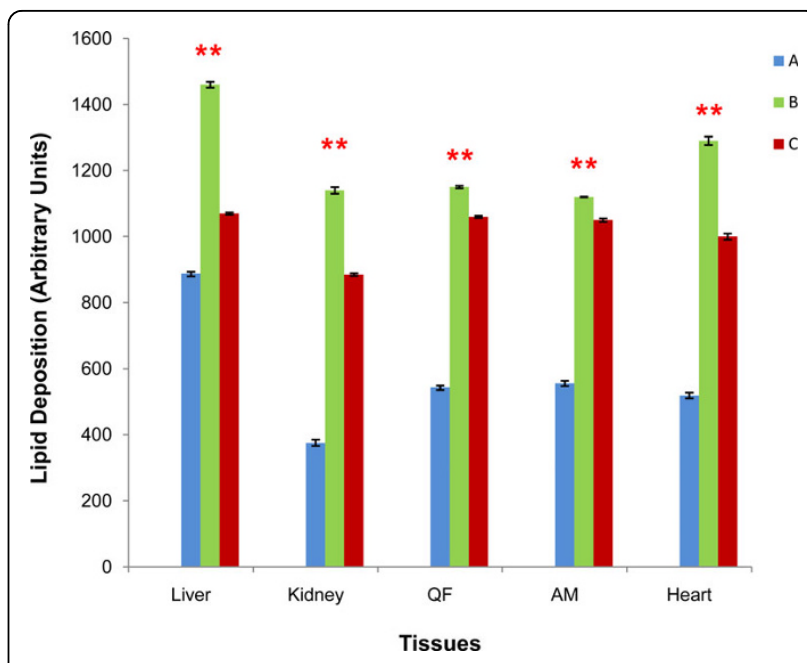

Figure 7 Comparison of tissue lipid deposition. Lipid deposition in tissues studied, measured in arbitrary units (AU). Sections of VAT and SAT were used as positive controls. ${ }^{* *}$ indicates significant increase in lipid deposition when comparing between Group A with each of Groups $B$ and $C$, and a significant decrease in lipid deposition in Group $C$ compared to B $(p<0.01)$. [Group A: rats fed on normal diet without $G A$; Group B: rats fed on high-fat diet without GA; Group C: rats fed on high-fat diet and given 100 mg/kg of $\mathrm{GA}]$.

an increase of $39.18 \%$ and $17.00 \%$ respectively when comparing groups $\mathrm{B}$ and $\mathrm{C}$ with $\mathrm{A}$ and a decrease of $26.71 \%$ in group $C$ compared to B. Mean lipid deposition in both kidneys from groups $\mathrm{A}, \mathrm{B}$ and $\mathrm{C}$ were $3.75 \times 10^{2} \pm 10.39 \mathrm{AU}, 1.41 \times 10^{3} \pm 10.04 \mathrm{AU}$ and 8.85 $\times 10^{2} \pm 4.12 \mathrm{AU}$ respectively, indicating a $67.11 \%$ and $57.63 \%$ increase in groups $\mathrm{B}$ and $\mathrm{C}$ relative to $\mathrm{A}$ and a $22.37 \%$ decrease in group $C$ relative to $B$. For the three muscle groups studied, QF lipid deposition showed a $52.70 \%$ and $48.68 \%$ increase in groups $B$ and $C$ relative to $\mathrm{A}$ and $7.83 \%$ decrease in group $\mathrm{C}$ relative to $\mathrm{B}$ (group $\mathrm{A}, 44 \times 10^{2} \pm 5.02 \mathrm{AU} ; \mathrm{B}, 1.15 \times 10^{3} \pm 3.74 \mathrm{AU} ; \mathrm{C}$, $\left.1.06 \times 10^{3} \pm 3.00 \mathrm{AU}\right), \mathrm{AM}$ lipid deposition charted a $50.36 \%$ and $47.05 \%$ increase in groups $B$ and $C$ relative to $\mathrm{A}$ and an accompanying $6.25 \%$ decrease in group $\mathrm{C}$ relative to B (group A, $5.56 \times 10^{2} \pm 7.53 \mathrm{AU} ; \mathrm{B}, 1.12 \times$ $10^{3} \pm 1.44 \mathrm{AU} ; \mathrm{C}, 1.05 \times 10^{3} \pm 5.47 \mathrm{AU}$ ) and heart lipid deposition showed an increase of $59.77 \%$ and $48.1 \%$ in groups B and C relative to A and a decrease of $22.48 \%$ in group $C$ relative to $B$.

\section{Discussion}

Numerous studies have revealed that high-fat diets promote hyperglycemia and whole-body IR. It is generally accepted that high-fat diets can be used to generate a valid rodent model for the MetS with IR [19]. Overfeeding of animals with high-fat diet of more than $50 \%$ of calories as fat for approximately five weeks is sufficient 
to initiate moderate obesity and often results in IR $[20,21]$. In the present study, rats were fed a high-fat diet with $60 \%$ of calories from vegetable shortening for four weeks. Rats fed a high-fat diet consumed significantly more calories on a per day basis compared to the controls which were only fed standard rat chow.

In the insulin resistant state, the decrease in insulinmediated suppression of lipolysis in adipocytes promotes the release of fatty acids which inhibits LPL activity [22]. When supply of fatty acids exceeds tissue demand, fatty acids would probably bind to LPL and displace it from its binding sites, thereby rendering them non-functional [23]. LPL expression of rats fed on high-fat diet without GA (group B) was down-regulated in all non-hepatic tissues compared to the controls (group A). The downregulation of LPL in the adipose tissues, muscles and kidney under study may be due to inflammatory mediators such as tumour necrosis factor-alpha (TNF- $\alpha$ ) which are found to be elevated in obesity and insulin resistant states [24]. Its inhibition of LPL gene transcription is suggested to be mediated in part by blocking the nuclear-factor-Y/CCAAT interactions with LPL promoter $[6,25]$. However, the increase in TNF- $\alpha$ level renders an opposing effect in the liver. According to Wang and Eckel [26], LPL is not normally expressed in the adult liver of animals but can be expressed under specific physiological and pathological conditions. A single dose of TNF- $\alpha$ can cause a significant increase in LPL mRNA levels in the liver. However, the detailed mechanism of such induction is not well understood. The increase in hepatic LPL activity and its concomitant decrease in the non-hepatic tissues could have resulted in greater partitioning of plasma TAG to the liver and increased hepatic uptake of FFAs. This would lead to an increase in the secretion of VLDL-TAG and apolipoprotein B100 (apoB100) from the liver [27], and hence may account for the observed hypertriglyceridaemia in group B compared to group A.

In rats on high-fat diet given GA (group C), LPL expression was up-regulated in all non-hepatic tissues, a condition that opposes that seen in group B. It was postulated that GA results in the up-regulation of LPL expression via the activation of PPAR class nuclear receptors since the LPL gene was found downstream of the transcriptionally active PPRE [5]. Of the tissues in which LPL expression was up-regulated, the highest upregulation took place mainly in the muscles (AM, QF and heart) compared to the SAT and VAT (Figure 2). This suggest that GA may exhibit a higher potency in activating PPAR $\alpha$ than PPAR $\gamma$ PPAR $\alpha$ is highly expressed in the heart, muscles, liver and kidney in which it has a crucial role in controlling fatty acid oxidation [28], while PPAR $\gamma$ is highly expressed in the adipocytes where it triggers adipocyte differentiation and lipogenesis [6]. The activation of PPAR $\alpha$ may lead to a direct up-regulation of LPL expression and also downregulate apo-CIII, an inhibitor of LPL [29] that is up-regulated in the insulin resistant state [8]. The downregulation of LPL expression in the liver might be due to the reduction in macrophage-derived TNF- $\alpha$ in the adipose tissue. According to Jeong and Yoon [30], PPAR $\alpha$ activation in adipose tissue decrease mRNA levels of TNF- $\alpha$ which eventually inhibit adipocyte hypertrophy in obese animals. Hence, GA is postulated to activate PPAR $\alpha$ in the adipose tissues to decreases TNF- $\alpha$ production and subsequently down-regulate LPL in the liver. The end effect of these is that GA thus promotes partitioning of lipids away from the liver into the oxidative tissues.

Improvement in lipid profile following GA treatment in obese-induced rat was similar to that previously reported by Lim et al. [31] in lean rats, but with a more prominent hypotriglyceridemic and HDL-raising effect. The hypertriglyceridaemia observed in patients with the MetS and T2DM originates from (i) lipolysis of TAG store from adipose tissue that causes elevated FFA flux to the liver and hence, increased hepatic TAG synthesis and (ii) inhibition of lipolysis of chylomicrons and VLDL due to decreased LPL levels [8]. Our present study indicated that GA administration in obese rats could curb such development by its selective induction of LPL expression in the non-hepatic tissues to promote catabolism of circulating TAG-rich lipoproteins and prevent further uptake of FFA into the liver by down-regulating hepatic LPL expression. More importantly, GA induced a significant increase in HDL levels in the obese rats. Elevating HDL-cholesterol may serve as a more attractive treatment alternative instead of lowering LDL cholesterol as dyslipidaemia is often characterized by a normal range of serum LDL-cholesterol, but with a predominance of the more atherogenic small, dense LDL rather than the less atherogenic large, buoyant LDL particles [7]. The atheroprotective effect of HDL is exerted through its ability to counteract LDL oxidation, the major initiating event that prompts the development of atherosclerosis. The HDL particle, by virtue of the antioxidative properties of its attached apo A-I, paraoxonase and glutathione peroxidase, reduces the oxidative modification of LDL by quenching the oxygen-derived free radicals generated from LDL oxidation [32]. Hence, various pharmacological interventions have been focused on raising HDL-cholesterol levels [32].

Obesity induced-IR results in profound dysregulation in the glucose homeostasis, and produces elevations in fasting and postprandial glucose levels [33]. As seen in the present study, the mean blood glucose concentration was increased in group B compared to group A. With the development of visceral obesity, the high circulating FFA 
leads to IR that promotes a dual effect to enhance hyperglycaemia by (i) down-regulating the insulin-sensitive glucose transporter 4 (GLUT4) via the Randle cycle and hence promotes an accumulation of glucose in the circulation and (ii) stimulating hepatic gluconeogenesis by antagonizing the action of insulin in the liver (hepatic IR) [8]. GA-treated rats in group $\mathrm{C}$ demonstrated a significant decrease in fasting blood glucose compared to group B. The reduction in fasting blood glucose of the GA-treated group is proposed to be accounted for by increased tissue glucose uptake via GLUT4. PPAR- $\gamma$ activation in the adipose tissue has been shown to increase the expression of the $\mathrm{c}-\mathrm{Cbl}$ associating protein (CAP) that is important for the translocation of GLUT4 to the cell surface [33] and inhibition of 11 $\beta$-HSD1 may also exhibit similar effect by attenuating the inhibition of muscle GLUT4 translocation by active glucocorticoids [34]. These effects may therefore increase glucose disposal, giving a decrease in circulating glucose levels. More importantly, both $11 \beta-$ HSD1 inhibition and PPAR- $\gamma$ agonism have also been associated with reduced expression of phosphoenolpyruvate carboxykinase (PEPCK) and glucose-6-phosphatase (G6Pase) [35,36], the two ratelimiting enzymes of the gluconeogenesis pathway that is aberrantly induced in T2DM patients [34]. Uncontrolled, accelerated gluconeogenesis accounts for $90 \%$ of hepatic glucose output in T2DM patients and is thereby a significant contributor to hyperglycaemia [35].

Besides a significant reduction in blood glucose concentration in group $\mathrm{C}$, mean serum insulin concentration was also reduced as compared to group B. This might be due to improved glucose-sensing proteins in the pancreatic $\beta$-cells since $\beta$-cells controls insulin secretion in response to blood glucose concentration [37]. Briefly, both the GLUT2 transporter and the enzyme glucokinase (GK) are components of the glucose-sensing apparatus of the $\beta$-cells whose expression are both decreased in diabetes. With this, the glucose threshold for insulin secretion is also decreased, leading to aberrant insulin secretion and hyperinsulinaemia. PPAR- $\gamma$ activation is shown to restore both GLUT2 and GK expression [36]. Hence the glucose threshold for insulin secretion is increased, reducing insulin secretion. The HOMA-IR is used for the assessment of insulin sensitivity from basal (fasting) glucose and insulin levels; a higher value indicating lower insulin sensitivity (higher insulin resistance) and vice versa [38]. The HOMA-IR index decrease in group $\mathrm{C}$ was significant compared to group B - indicating an improvement in insulin sensitivity in rats on high-fat diet and given $100 \mathrm{mg} / \mathrm{kg}$ of GA.

Chronic obesity has been associated with non-adipose tissue lipid accumulation - a condition known as tissue steatosis $[8,39]$. During conditions of chronic caloric excess, a compensatory mechanism first occur in the leptin-responsive state whereby the surplus FFA up-regulates PPAR $\alpha$ and promote the compensatory oxidation of the surplus FFA, with the excess energy dissipated as heat. As such process continues, such caloric excess is no longer compensated and in the leptin-unresponsive state, the surplus FFA activates PPAR $\gamma$ instead, leading to up-regulation of the lipogenic enzymes that cause ectopic TAG accumulation [39]. Leptin resistance has been reported to occur in late phases in both rat and human diet-induced obesity [39]. Our present study has shown that lipid depositions in all the tissues of group $\mathrm{C}$ rats were significantly reduced compared to group B. We postulate that such observation is accounted for by GA activation of PPAR $\alpha$ that induces the expression of lipid-catabolizing genes such as carnitine palmitoyltransferase-1 (CPT-1), acyl CoA oxidase (ACO) and uncoupling protein (UCP-2) that are induced normally in the state of compensated caloric excess aforementioned. Tissue lipid accumulation has been associated with obesity-related IR $[40,41]$ and these are mediated by TAG-derived metabolites that inhibits insulin signal transduction [42]. Thus, our observation of GA-mediated improvement in insulin sensitivity may be related to such decrease in tissue lipid as well.

\section{Conclusion}

Our study has indicated that daily oral administration of $100 \mathrm{mg} / \mathrm{kg}$ of GA to high-fat dietinduced obese rats for 28 days led to significant improvement in insulin sensitivity, together with an apparent hypotriglyceridaemic and HDL-raising effect. LPL expression was upregulated mainly in the oxidative tissues and this may promote catabolism of the TAG-rich VLDL and chylomicron that usually accumulate in the circulation of MetS patients. Lastly, a decrease in tissue lipid deposition was observed with GA administration - possibly associated with an increase in fatty acid oxidation.

\section{Methods}

\section{Animal treatment}

The use and handling procedure of animals in this research project had been approved by the Monash University Animal Ethics Committee (AEC Approval Number: SOBSB/MY/2007/22). 24 male Sprague-Drawley rats (Rattus norvegicus) with an initial weight between $160 \mathrm{~g}$ to $200 \mathrm{~g}$ were randomly chosen and were housed individually in plastic cages with a 12:12-h light-dark cycle - lights starting at 0600 hours. The room was kept at $23.0^{\circ} \mathrm{C} \pm 1.0^{\circ} \mathrm{C}$. Before the experiment, rats in all groups were fed ad libitum with free access to standard rat chow (Gold Coin, Malaysia) and tap water. At the start of this experiment, each of the 3 groups were subjected to different dietary composition and treatment Group A was fed on a normal diet; Group B was fed on high-fat diet; Group C was fed on high-fat diet and 
given $100 \mathrm{mg} / \mathrm{kg}$ of GA through a feeding bottle. The high-fat diet pellets were prepared by mixing powdered rat chow to vegetable shortening in a ratio of $2: 3$. All three groups of rats were fed and treated for 28 days. The amount of food and water or GA consumed was recorded daily.

\section{Sample collection}

Rats in all groups were fasted for approximately 12 hours prior to sacrifice. The rats were anaesthetized by intraperitoneal injection of $150 \mathrm{mg} / \mathrm{kg}$ of sodium pentobarbital (Nembutal) and dissection was carried out between 0800 and 1000 hours. Blood was drawn from the apex of the cardiac ventricle and five drops of blood were collected into a microcentrifuge tube containing a mixture of EDTA and NaF in a 1:2 (w/w) ratio. This aliquot of blood will be used for blood glucose determination. The remaining blood sample was collected into a sterile Falcon tube and centrifuged at $12,000 \times \mathrm{g}$ for 10 minutes. The serum supernatant was aliquoted into microcentrifuge tubes and stored at $-80^{\circ} \mathrm{C}$ until required for analysis. The seven tissues of interest, namely, the heart, kidney, liver, AM, QF, VAT and SAT were promptly harvested and immediately flash-frozen in liquid nitrogen and stored at $-80^{\circ} \mathrm{C}$.

\section{Blood biochemistry analysis}

Blood glucose was determined using the Trinder's glucose oxidase method while serum insulin was determined using the Rat/Mouse Insulin ELISA Kit (Linco Research, USA). The HOMA-IR was calculated as the product of fasting blood glucose and serum insulin divided by 22.5 [38]. Serum FFA, TAG and total cholesterol were determined using the Zenbio 96- well Serum/ Plasma Fatty Acid Kit Non-Esterified Fatty Acids Detection 100 point kit (Zenbio, USA), Randox Triglycerides Kit (Randox, UK) and Randox CH200 Cholesterol Kit (Randox, UK) respectively. HDL-cholesterol was determined using the aforementioned cholesterol kit after precipitation of HDL using the Randox CH203 HDL Precipitant Kit (Randox, UK). LDL-cholesterol was calculated using the levels of total cholesterol, TAG, HDLcholesterol obtained using the Friedewald formula [43].

\section{Real time reverse transcription polymerase chain reaction (qRT-PCR) of LPL gene}

Qiagen RNeasy Mini kit (Qiagen, USA) was used to isolate the total RNA from the liver, kidney, AM and QF while Qiagen RNeasy Lipid Tissue Mini kit was used to isolate the total RNA from SAT and VAT (Qiagen, USA). The purity of the RNA was determined by determining the absorbance values at $260 \mathrm{~nm}$ and $280 \mathrm{~nm}$ $\left(\mathrm{A}_{260} / \mathrm{A}_{280}\right.$ ratio) where a ratio of $1.9-2.1$ is considered pure. Promega RQ1 RNase-free DNase (Promega, USA) was used for the RNase-free DNase treatment and lastly, Qiagen Omniscript Reverse Transcriptase kit (Qiagen, USA) was used for cDNA synthesis. Relative LPL expression was determined by qT-PCR using the Comparative $\mathrm{Ct}(\Delta \Delta \mathrm{Ct})$ Method, normalized to the BAC gene. Sequence of primers and probes specific to Rattus norvegicus LPL [GenBank: BC081836] and BAC [GenBank: BC063166] mRNA are as follows:

LPL, forward: 5'-CAGCAAGGCATACAGGTG-3'

LPL, reverse: '-CGAGTCTTCAGGTACATCTTAC-3'

LPL, probe: 5'-(6-FAM) TTCTCTTGGCTCTGACC (BHQ1)-3'

BAC, forward: 5'-GTATGGGTCAGAAGGACTCC-3'

BAC, reverse: 5'-GTTCAATGGGGTACTTCAGG-3'

BAC, probe: 5'-(TET) CCTCTCTTGCTCTGGGC (BHQ1)-3'

Agarose gel electrophoresis was performed on amplicons produced from qRT-PCR to assess primer specificity.

\section{Tissue lipid quantification}

Frozen tissues were cut into cubes of $5 \times 5 \times 5 \mathrm{~mm}$ on a sterile petri dish and fixed onto a cryotome at $-25^{\circ} \mathrm{C}$ using the Optimal Cutting Temperature (OCT) Compound (Leica, Germany). Sections of $5 \mu \mathrm{m}$ thick were stained with ORO using the method of Koopman et al. [44] and captured at 400× magnification. Lipid depositions for all tissues were calculated as per Goodpaster $e t$ al. [40]. Briefly, captured images were converted to gray scale on Image J software and the threshold for staining intensity was adjusted to selectively pick up lipid droplets. Pixels with intensities of $150 \pm 30$ arbitrary unit (AU) were selected (intensity ranges from $0 A U$ to 255AU; 0AU represented complete staining and 255AU represented no staining). The mean of eight values from eight contiguous views captured was used to determine the level of lipid deposition in arbitrary units (AU).

$$
\text { Lipid deposition }=\frac{\text { Area stained }(\%) \text { Mean stain intensity }}{10^{6}}
$$

\section{Statistical analysis}

Statistical analysis for LPL expression was performed using the Relative Expression Software Tool $\left(\mathrm{REST}^{\odot}{ }^{\odot}\right)$ MCS Beta 2006. All other data were analyzed using Statistics Package for the Social Sciences (SPSS) for Windows Version 16.0. Data distribution was analyzed using the Kolmogorov-Smirnov normality test. Data with parametric distribution were then analyzed using Analysis of Variance (ANOVA) and if the results were significant, a Post Hoc Scheffe test was performed. Data with nonparametric distribution was analyzed using KruskallWallis test. All data in this study were found to be 
parametric and hence were all reported as mean \pm standard error. In all analyses, a p-value of $\leq 0.05$ was considered statistically significant.

\begin{abstract}
Abbreviations

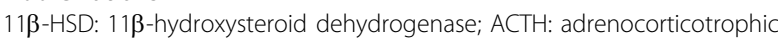
hormone; ACO: acyl CoA oxidase; AM: abdominal muscle; apo: apolipoprotein; BAC: $\beta$-actin; CAP: $c$-Cbl associating protein; CPT-1: carnitine palmitoyltransferase-1; FFA: free fatty acids; GA: glycyrrhizic acid; GE: glycyrrhetic acid; GK: glucokinase; GLUT: glucose transporter; HDL: highdensity lipoprotein; HOMA-IR: homeostasis model assessment of insulin resistance; IR: insulin resistance; LDL: low-density lipoprotein; LPL: lipoprotein lipase; MetS: metabolic syndrome; ORO: Oil Red O; PEPCK:

phosphoenolpyruvate carboxykinase; G6Pase: glucose- 6-phosphatase; PPAR: peroxisome proliferator-activator receptor; PPRE: peroxisome proliferator response element; QF: quadriceps femoris; SAT: subcutaneous adipose tissue; T2DM: type 2 diabetes mellitus; TAG: triacylglycerol; TNF- $\alpha$ : tumour necrosis factor-alpha; TZDs: thiazolidinediones; UCP-2: uncoupling protein; VAT: visceral adipose tissue; VLDL: very-low-density lipoprotein; WHHL: watanabe heritable hyperlipidemic
\end{abstract}

\section{Acknowledgements}

The study is funded in part by a grant from the Malaysian Ministry of Science, Technology and Innovation (02-02-10-SF0003).

\section{Author details}

${ }^{1}$ School of Science, Monash University Sunway Campus, Jalan Lagoon Selatan, Bandar Sunway 46150, Selangor Darul Ehsan, Malaysia. ${ }^{2}$ School of Medicine and Health Sciences, Monash University Sunway Campus, Jalan Lagoon Selatan, Bandar Sunway 46150, Selangor Darul Ehsan, Malaysia.

\section{Authors' contributions}

CHAE performed all data acquisition, analysis and interpretation and manuscript preparation. WYAL was involved in data interpretation and manuscript preparation. TSH and KAK participated in the coordination of the study and helped in drafting the manuscript. All authors read and approved the final manuscript.

\section{Competing interests}

The authors declare that they have no competing interests.

Received: 23 February 2010 Accepted: 29 July 2010

Published: 29 July 2010

\section{References}

1. Janus E: Metabolic syndrome and its relevance to Asia. International Congress Series 2004, 1262:535-537.

2. Balkau B, Valensi P, Eschwege E, Slama G: A review of the metabolic syndrome. Diabetes Metab 2007, 33:405-413.

3. Grundy S: Metabolic Syndrome Pandemic. Arterioscler Thromb Vasc Biol 2008, 28:629-636.

4. Pollare T, Vessby B, Lithell H: Lipoprotein lipase activity in the skeletal muscle is related to insulin sensitivity. Arterioscler Thromb Vasc Biol 1991, 11:1192-1203.

5. Kageyama H, Hirano T, Okada K, Ebara T, Kageyama A, Murakami T, Shioda S, Adachi M: Lipoprotein lipase mRNA in white adipose tissue but not in skeletal muscle is increased by pioglitazone through PPARgamma. Biochem Biophys Res Commun 2003, 305:22-27.

6. Preiss-Landi K, Zimmermann R, Hammerle G, Zechner R: Lipoprotein lipase: the regulation of tissue specific expression and its role in lipid and energy metabolism. Curr Opin Lipidol 2002, 13(5):471-481.

7. Kolovou GD, Anagnostopoulou KK, Cokkinos DV: Pathophysiology of dyslipidaemia in the metabolic syndrome. Postgrad Med J 2005, 81:358-366.

8. Lann D, LeRoith D: Insulin Resistance as the Underlying Cause for the Metabolic Syndrome. Med Clin N Am 2007, 91:1063-1077.

9. Koike T, Liang J, Wang X, Ichikawa T, Shiomi M, Liu G, Sun H, Kitajima S, Morimoto M, Watanabe T, Yamada N, Fan J: Overexpression of Lipoprotein Lipase in Transgenic Watanabe Heritable Hyperlipidemic Rabbits
Improves Hyperlipidemia and Obesity. J Biol Chem 2004, 279(9):7521-7529.

10. Jensen DR, Schlaepfer IR, Morin CL, Pennington DS, Marcell T, Ammon SM, Gutierrez-Hartmann A, Eckel RH: Prevention of diet-induced obesity in transgenic mice overexpressing skeletal muscle lipoprotein lipase. Am J Physiol Regul Integr Comp Physiol 1997, 273:683-689.

11. van Wijk JPH, de Koning EJP, Martens EP, Rabelink TJ: Thiazolidinediones and Blood Lipids in Type 2 Diabetes. Arterioscler Thromb Vasc Biol 2003, 23:1744-1749.

12. Mead JR, Irvine SA, Ramji DP: Lipoprotein lipase: structure, function, regulation and role in disease. J Mol Med 2002, 80:753-769.

13. Post SM, Duez H, Gervois PP, Staels B, Kuipers F, Princen HMG: Fibrates Suppress Bile Acid Synthesis via Peroxisome Proliferator-Activated Receptor- $\alpha$-Mediated Downregulation of Cholesterol $7 \alpha$-Hydroxylase and Sterol 27-Hydroxylase Expression. Arterioscler Thromb Vasc Biol 2001, 21:1840-1845.

14. Yki-Jarvinen H: Thiazolidinediones. N Engl J Med 2004, 351:1106-1118.

15. Shimono $K$, Tsutsumi $K$, Yaguchi $H$, Omura M, Sasano H, Nishikawa T: Lipoprotein lipase promoting agent, NO-1886, modulates adrenal functions: Species difference in effects of NO-1886 on steroidogenesis. Steroids 1999, 64:453-459.

16. Isbrucker RA, Burdock GA: Risk and safety assessment of the consumption of Licorice root (Glycyrrhiza sp.), its extract and powder as a food ingredient, with emphasis on the pharmacology and toxicology of glycyrrhizin. Regul Toxicol Pharmacol 2006, 46:167-192.

17. Wang Y, Porter WW, Suh N, Honda T, Gribble GW, Leesnitzer LM, Plunket KD, Mangelsdorf DJ, Willson TM, Sporn MB: A Synthetic Triterpenoid, 2-Cyano-3,12-dioxooleana-1,9-dien-28-oic Acid (CDDO), Is A Ligand for the Peroxisome Proliferator-Activated Receptor Gamma. Mol Endocrinol 2000, 14(10):1550-1556.

18. Sato M, Tai T, Nunoura Y, Yajima Y, Kawashima S, Tanaka K: Dehydrotrametenolic Acid Induces Preadipocyte Differentiation and Sensitizes Animal Models of Noninsulin-Dependent Diabetes Mellitus to Insulin. Biol Pharm Bull 2002, 15(1):81-86.

19. Buettner R, Parhofer KG, Woenckhaus M, Wrede CE, Kunz-Schughart LA, Scholmerich J, Bollheimer LC: Defining high-fat diet rat models: metabolic and molecular effects of different fat types. J Mol Endocrinol 2006, 36:485-501.

20. Moller DE, Kaufman KD: Metabolic Syndrome: A Clinical and Molecular Perspective. Annu Rev Med 2005, 56:45-62.

21. Fam BC, Morris MJ, Hansen MJ, Kebede M, Andrikopoulos S, Proietto J, Thorburn AW: Modulation of central leptin sensitivity and energy balance in a rat mode of diet-induced obesity. Diabetes Obes Metab 2006, 9:840-852.

22. Franssen R, Monajemi $H$, Stroes ERG, Kastelein JJP: Obesity and Dyslipidaemia. Endocrinol Metab Clin North Am 2008, 37:623-633.

23. Pulnilkunnil T, Rodrigues B: Cardiac lipoprotein lipase: Metabolic basis for diabetic heart disease. Cardiovasc Res 2006, 69:329-340.

24. Zechner R: The tissue-specific expression of lipoprotein lipase: implications for energy and lipoprotein metabolism. Curr Opin Lipidol 1997, 8:77-88.

25. Rosen ED, Spiegelman BM: Adipocytes as regulators of energy balance and glucose homeostasis. Nature 2006, 444(7121):847-853.

26. Wang $\mathrm{H}$, Eckel RH: Lipoprotein lipase: From gene to obesity. American journal of physiology. Adv Endocrinol Metab 2009, 297:E271-E288.

27. Adiels M, Olofsson SO, Taskinen MR, Boren J: Overproduction of very lowdensity lipoproteins is the hallmark of the dyslipidemia in the metabolic syndrome. Arterioscler Thromb Vasc Biol 2008, 28:1225-1236.

28. Evans RM, Barish GD, Wang YX: PPARs and the complex journey to obesity. Nature 2004, 10(4):1-6.

29. Lee $\mathrm{CH}$, Olson P, Evans RM: Minireview: Lipid Metabolism, Metabolic Diseases, and Peroxisome Proliferator-Activated Receptors. Endocrinology 2003, 144(6):2201-2207.

30. Jeong S, Yoon M: Fenofibrate inhibits adipocyte hypertrophy and insulin resistance by activating adipose PPAR $\alpha$ in high fat diet-induced obese mice. Exp Mol Med 2009, 41(6):397-405.

31. Lim WYA, Chia YY, Liong SY, Ton SH, Abdul Kadir K, Syed Husain SNA: Lipoprotein lipase expression, serum lipid and tissue lipid deposition in orally administered glycyrrhizic acid-treated rats. Lipids Health Dis 2009, 8(1):Article 31 
32. Assmann G, Nofer J: Atheroprotective Effects of High-Density Lipoproteins. Annu Rev Med 2003, 54:321-341.

33. Saltiel AR, Kahn R: Insulin signaling and the regulation of glucose and lipid metabolism. Nature 2001, 414:799-805.

34. Vegiopoulos A, Herzig S: Glucocortocoids, metabolism and metabolic diseases. Mol Cell Endocrinol 2007, 275:43-61.

35. Alberts P, Engblom L, Edling N, Forsgren M, Klingstrom G, Larsson C, Ronquist-Nii Y, Ohman B, Abrahmsen L: Selective inhibition of 11 betahydroysteroid dehydrogenase type 1 decreases blood glucose concentrations in hyperglycaemic mice. Diabetologia 2002, 45:1528-1532.

36. Kim H, Ahn Y: Role of Peroxisome Proliferator-Activated Receptor-gamma in the Glucose-sensing Apparatus of Liver and Beta-cells. Diabetes 2004, 53(1):S60-565.

37. Xu ZK, Chen NG, Ma CY, Meng ZX, Sun YJ, Han X: Role of Peroxisome Proliferator-Activated Receptor Gamma in Glucose-Induced Insulin Secretion. Acta Biochim Biophys Sin 2006, 38(1):1-7.

38. Vogeser M, Konig D, Frey I, Predel HG, parhofer KG, Berg A: Fasting serum insulin and the homeostasis model of insulin resistance (HOMA-IR) in the monitoring of lifestyle interventions in obese persons. Clin Biochem 2007, 40:964-968.

39. Unger RH, Orci L: Diseases of liporegulation: new perspective on obesity and related disorders. FASEB J 2001, 15:312-321.

40. Goodpaster BH, Theriault R, Watkins SC, Kelley DE: Intramuscular Lipid Content Is Increased in Obesity and Decreased by Weight Loss. Metabolism 2000, 49(4):467-472.

41. Athenstaedt K, Daum G: The life cycle of neutral lipids: synthesis, storage and degradation. Cell Mol Life Sci 2006, 63:1355-1369.

42. Muoio DM, Newgard CB: Obesity-Related Derangements in Metabolic Regulation. Annu Rev Biochem 2006, 75:367-401.

43. Friedewald WT, Levy Rl, Fredrickson DS: Estimation of the concentration of LDL-cholesterol in plasma without use of the preparative ultracentrifuge. Clin Chem 1972, 18:499-502.

44. Koopman R, Schaart G, Hesselink MKC: Optimisation of Oil Red O staining permits combination with immunofluorescence and automated quantification of lipids. Histochem Cell Biol 2001, 116:63-68.

doi:10.1186/1476-511X-9-81

Cite this article as: Eu et al.: Glycyrrhizic acid improved lipoprotein lipase expression, insulin sensitivity, serum lipid and lipid deposition in high-fat diet-induced obese rats. Lipids in Health and Disease 2010 9:81.

\section{Submit your next manuscript to BioMed Central and take full advantage of:}

- Convenient online submission

- Thorough peer review

- No space constraints or color figure charges

- Immediate publication on acceptance

- Inclusion in PubMed, CAS, Scopus and Google Scholar

- Research which is freely available for redistribution

Submit your manuscript at www.biomedcentral.com/submit
Biomed Central 